\title{
O PROCESSO DE COLABORAÇÃO NA PRODUÇÃO DE TEXTOS EM ESCRITA DAS LÍNGUAS DE SINAIS (ELIS): UM ESTUDO SOBRE AS INTERAÇÕES ENTRE ALUNOS SURDOS
}

\author{
THE PROCESS OF COLLABORATION IN THE PRODUCTION OF TEXTS IN SIGN LANGUAGE \\ WRITING (ELIS): A STUDY ON THE INTERACTIONS BETWEEN DEAF STUDENTS
}

\author{
Guilherme Gonçalves de Freitas ${ }^{1}$, Francisco José Quaresma de Figueiredo ${ }^{1}$ \\ 1 Universidade Federal de Goiás (UFG), Goiânia, GO, Brasil \\ guilhermefreitaslibras@gmail.com, fquaresma@terra.com.br
}

Recebido em 10 set. 2018

Aceito em 23 nov. 2018

Resumo: Este estudo tem por objetivo investigar o processo de colaboração na produção de textos em escrita das línguas de sinais (ELiS), realizado individualmente e colaborativamente por alunos surdos. Como objetivo específico, buscamos verificar as percepções dos alunos acerca do processo de escrever em ELiS individualmente e colaborativamente. Os dados desta pesquisa advêm do estudo de Freitas (2016), do qual participaram quatro alunos surdos, de uma turma do curso de Letras: Libras da Universidade Federal de Goiás. Do ponto de vista metodológico, trata-se de um estudo de caso qualitativo, e os dados foram obtidos por meio de entrevistas, filmagens, questionários e textos dos participantes. Foram analisados seis textos, dos quais quatro foram escritos individualmente por cada participante, e dois que foram escritos em pares. A análise de dados baseou-se nas contribuições de Barros (2008, 2015, 2016), Figueiredo (2001, 2006, 2015) e Vygotsky (1998). Este trabalho visa responder às seguintes perguntas: i) Quais as percepções dos participantes acerca de escrever em ELiS individualmente e em pares? ii) Quais as possíveis contribuições do trabalho colaborativo na produção de textos em ELiS? Os resultados mostraram que a mediação entre os participantes, ao dialogarem sobre a escrita das línguas de sinais (ELiS), possibilitou-lhes aprender uns com os outros e a refletir sobre a forma correta para escrita do sinal em Libras/ELiS, feito que não ocorreu quando produziram seus textos individualmente. Esperamos que esta pesquisa possa trazer reflexões sobre o ensino de escrita de sinais dentro da perspectiva da aprendizagem colaborativa nos espaços educacionais no Brasil.

Palavras-chave: Escrita das línguas de sinais. ELiS. Língua de Sinais. Aprendizagem colaborativa. Interação.

\begin{abstract}
This study aims to investigate the process of collaboration in the production of texts in sign language writing (ELiS), carried out individually and collaboratively by deaf students. The data of this research comes from a study conducted by Freitas (2016), which had the participation of four deaf students who take Brazilian Sign Language (Libras) as a major at Universidade Federal de Goiás. From the methodological point of view, this is a qualitative case study, and data were obtained through interviews, video recordings, questionnaires and the texts written by the participants. Six texts were analyzed, four of which were written individually by each participant, and two were written in pairs. Data analysis was based on the contributions of Barros (2008, 2015, 2016), Figueiredo (2001, 2006, 2015) and Vygotsky (1998). This paper aims to answer the following questions: i) What are the participants' perceptions about writing in ELiS individually and in pairs? ii) What are the possible contributions of collaborative work in the production of texts in ELiS? The results showed that mediation among the participants, when they talked about sign language writing (ELiS), allowed them to learn from each other and to reflect on the correct way to write the sign in Libras/ELiS, a fact that did not occur when they produced their texts individually. We hope that this research may bring reflections on the teaching of sign writing within the perspective of collaborative learning in educational spaces in Brazil.
\end{abstract}

Keywords: Sign language writing. EliS. Sign language. Collaborative learning. Interaction. 


\section{INTRODUÇÃO}

Vários pesquisadores, no Brasil e em outras partes do mundo, têm realizado estudos sobre a relevância da colaboração na produção textual de alunos aprendendo uma segunda língua (L2) e língua estrangeira (LE) (ALCÂNTARA; SIQUEIRA; VALASKI, 2004; BASSI, 2006; CARVALHO, 2002; FIGUEIREDO, 2001, 2006, 2015; WOBETO, 2012, entre outros). Os resultados dessas pesquisas nos mostram que a interação e a colaboração favorecem a aprendizagem e criam oportunidades para os aprendizes construírem conhecimento.

Sendo assim, por entendermos a importância da colaboração no processo de aprendizagem de línguas, pretendemos, com esta pesquisa, verificar a relevância da abordagem colaborativa na produção de textos em Escrita das Línguas de Sinais ${ }^{1}$ (ELiS).

Os dados desta pesquisa advêm de um trabalho de conclusão de curso (TCC) ${ }^{2}$ realizado por Freitas (2016), cujo objetivo central foi investigar os processos de interações na produção de textos em ELiS, realizadas de forma individual e colaborativa por alunos surdos. A motivação para a execução deste estudo se pautou no fato de que as pesquisas que abordam a produção textual em escrita de sinais (ELiS) serem ainda incipientes no Brasil.

As propostas da aprendizagem colaborativa que contemplam as línguas orais têm sido frequentemente aplicadas de forma bem-sucedida no contexto de ensinoaprendizagem de língua de sinais, em específico, a Libras ${ }^{3}$. Desse modo, o trabalho em pares poderá promover uma dinâmica mais agradável na relação alunos/alunos

\footnotetext{
${ }^{1}$ Entende-se por sinais a "combinação do movimento das mãos com um determinado formato em um determinado lugar, podendo este lugar ser uma parte do corpo ou um espaço em frente ao corpo" (FELIPE, 2001, p. 20). Os sinais, nas línguas sinalizadas, assemelham-se às palavras nas línguas orais.

2 Este estudo está inserido numa pesquisa macro intitulada "Estudos sobre os efeitos da colaboração no processo de ensino-aprendizagem de línguas em contextos presenciais e virtuais", sob a responsabilidade do Professor Doutor Francisco José Quaresma de Figueiredo, um dos autores deste artigo. A referida pesquisa está inserida na Plataforma Brasil e foi aprovada no Comitê de Ética em Pesquisa (CEP) da Universidade Federal de Goiás, com o parecer de ㄲo 2.363.676.

3 Para mais detalhes sobre as contribuições neste contexto, veja, por exemplo, Freitas (2016), Oliveira e Figueiredo (2017) e Oliveira-Silva (2017).
} 
e alunos/professor, ao dialogarem sobre qualquer tarefa, seja de escrita, fala (oral ou sinalizada), leitura e planejamento (SWAIN; BROOKS; TOCALLI-BELLER, 2002).

Estudos como os de Antón (1999), Figueiredo (2001) e Nunan (1991) chamam a nossa atenção para a aplicação de metodologias de ensino comunicativo em sala de aula. De acordo com esses autores, a abordagem comunicativa maximiza as oportunidades de os alunos dialogarem em sala de aula. Assim, o aprendiz é visto como um indivíduo atuante e ativo nesse processo de aprendizagem. E o professor, por sua vez, é visto como facilitador e mediador nas negociações que envolvem forma, conteúdo e significado durante as interações realizadas em classe.

Como parte dos objetivos deste estudo, buscamos verificar os benefícios da colaboração para a aprendizagem de línguas cuja modalidade ${ }^{4}$ se diferencia das línguas orais, como, por exemplo, a Libras, que se estrutura por meio da modalidade visuoespacial (QUADROS; KARNOPP, 2004). Este artigo visa responder às seguintes perguntas: i) Quais as percepções dos participantes acerca de escrever em ELiS individualmente e em pares? ii) Quais as possíveis contribuições do trabalho colaborativo na produção de textos escritos em ELiS?

Este artigo está estruturado da seguinte forma: primeiramente, definimos o conceito de escrita, ampliando para o contexto de escrita de sinais. Posteriormente, trabalhamos com o arcabouço teórico da aprendizagem colaborativa, que, por sua vez, dialoga com os pressupostos da teoria sociocultural de Vygotsky. Justificamos a escolha desses construtos por acreditarmos que a construção de conhecimento é favorecida por meio das interações entre os aprendizes. Ao trabalharem juntos, eles podem solucionar suas dificuldades com seus pares de forma mútua. Em seguida, apresentamos a metodologia, discutindo os resultados encontrados e, por fim, tecemos algumas considerações finais.

\footnotetext{
4 O termo "modalidade" é entendido como o meio em que as línguas são produzidas e percebidas pelos falantes, podendo ser representadas pela escrita, pela produção oral ou pela produção sinalizada (OLIVEIRA-SILVA, 2017). As línguas sinalizadas ou propriamente conhecidas no meio acadêmico como línguas "visuoespaciais" são todas as que se organizam no espaço de sinalização (FAULSTICH, 2007). De um modo geral, 'espacial' refere-se ao ponto e à articulação da sinalização, e 'visuo' refere-se à característica do sujeito surdo que tem na visão o principal recurso para receber input. Por sua vez, línguas orais são todas as línguas que são produzidas e 'percebidas' pelos falantes por meio do canal boca, olho e ouvido. Dessa forma, o português, o inglês, o espanhol, o francês, o italiano, entre outras, são línguas orais.
} 


\section{ALGUNS CONCEITOS TEÓRICOS}

Na primeira parte desta seção, apresentamos alguns estudos sobre o processo de escrita. Na segunda, discutimos os principais construtos da teoria sociocultural e da aprendizagem colaborativa.

\subsection{A ESCRITA COMO MEIO DE REPRESENTAÇÃO LINGUÍSTICA E DE COMUNICAÇÃO}

Os pressupostos teóricos que fundamentam reflexões sobre o papel da escrita como meio de representação e de comunicação evidenciam que esse sistema é tido como uma espécie de linguagem e como ferramenta psicológica para o desenvolvimento do indivíduo em suas relações com o meio social (VYGOSTKY, 1998).

A escrita é vista como o principal instrumento no contexto educacional, e isso ocorre por ser uma modalidade que registra, de forma concreta, qualquer enunciado oral, dos mais simples aos mais elaborados. Além disso, a escrita possibilita ao aluno fazer anotações e, com isso, ter algum documento a ser consultado fora de sala de aula, não ficando preso, por exemplo, a materiais disponibilizados apenas em livros, apostilas ou na internet.

No contexto do ensino de línguas, essa ferramenta tem sido uma estratégia usada por muitos alunos para internalização de um conteúdo. Araújo e Figueiredo (2015, p. 4) afirmam que é por meio da escrita que "o indivíduo tem a oportunidade de reforçar algum conteúdo já estudado, como um item gramatical ou palavras de vocabulário, como também por ter a oportunidade de expor seus pensamentos e ideias". No processo de ensino-aprendizagem de Libras, a escrita de línguas orais, no caso o português, pode auxiliar no registro da língua sinalizada. Entretanto, essa estratégia não possibilita o registro apropriado dessa língua, visto que a Libras e o português são línguas de modalidades diferentes. Em muitos casos, os aprendizes buscam associar, por meio de representações criativas, o que é ensinado a eles nas 
aulas de Libras. Isso ocorre por não existir nenhuma escrita das línguas de sinais reconhecida de forma oficial ${ }^{5}$ no Brasil. Sendo assim, ao aprender a Libras, os aprendizes são, de modo geral, obrigados a recorrer ao modelo de escrita de línguas orais $^{6}$, apostilas ou vídeos para internalizar um sinal aprendido durante as aulas.

Tendo em vista a potencialidade da escrita no meio social e as contribuições dela para o indivíduo, devemos estimular a comunidade surda a se expressar por meio da escrita das línguas de sinais (ELiS). Desse modo, os surdos podem, por exemplo, registrar a sua própria língua, tendo, assim, a oportunidade de desenvolver autonomia linguística ao poderem expressar sentimentos, emoções e desejos. E os alunos ouvintes podem também fazer uso desse recurso quando estão aprendendo a língua de sinais.

Atualmente, muitos são os desafios para a aplicabilidade da escrita de sinais em contextos educacionais. Muitos desses desafios ocorrem, por exemplo, por ainda haver poucos profissionais capacitados em utilizar e ensinar, em sala de aula, a língua escrita e sinalizada simultaneamente e, também, por ainda existir certa "resistência" acerca do uso da escrita das línguas de sinais. Quadros e Schmiedt (2006, p. 31) afirmam que "[l]er e escrever em sinais e em português são processos complexos que envolvem uma série de tipos de competências e experiências de vida que as crianças trazem".

Assim, por meio do sistema ELiS, elaborado por Barros (2008, 2015, 2016), os sujeitos surdos também têm a possibilidade de se comunicarem por escrito ${ }^{7}$, assim como o fazem os sujeitos ouvintes com a escrita das línguas orais. Além disso, a ELiS possibilta ao sujeito ouvinte registrar enunciados na língua que está aprendendo, no caso, a Libras. Fernandes (2013, p. 16) afirma que

\footnotetext{
${ }^{5}$ Apesar de ainda não existir um sistema de escrita oficial em línguas de sinais, existem algumas propostas que evidenciam os aspectos linguísticos das línguas de sinais no Brasil, como, por exemplo: o SignWriting, Sistema de Escrita da Língua de Sinais (SEL), ELiS e recentemente a Visografia.

${ }^{6}$ Atualmente, o ensino da escrita das línguas de sinais ocorre principalmente em contextos de ensino superior (BARROS, 2015).

7 Por meio da fonte ELiS, os indivíduos podem também registrar a escrita de sinais por meio do computador.
} 
[a] ELiS tem o objetivo de dar ao sujeito surdo o direito de se expressar em sua própria língua, além da possibilidade de se registrar qualquer documento na modalidade escrita em sua própria língua, no caso, em sua $\mathrm{L} 1$, dando às línguas de sinais maior independência e visibilidade. (FERNANDES, 2013, p. 16)

A difusão da ELiS no contexto de educação inclusiva ainda está em fase de implementação, apesar de o seu ensino já estar ocorrendo na formação de professores e em cursos de qualificação, oferecidos por alunos do Estágio no curso de Letras: Libras da Universidade Federal de Goiás (UFG) (FREITAS, 2016). No contexto de ensino superior, esse sistema passa por um processo de consolidação. No curso de Letras: Libras, da UFG, está presente na matriz curricular como disciplina obrigatória desde 2009. Tem sido também utilizada em outras instituições de ensino superior, como, por exemplo, a Universidade de Grande Dourados (UFGD), a Universidade Federal do Mato Grosso (UFMT) e o Instituto Federal de Goiás (IFG), campus Aparecida de Goiânia, no curso de Pedagogia Bilíngue.

A ELiS é de base alfabética linear, e sua representação ocorre da esquerda para a direita. Para escrever em ELiS, é preciso, primeiramente, compreender a natureza dos visografemas, isto é, os caracteres que compõem o sistema ELiS. É um sistema que contém 95 caracteres, divididos em quatro grupos: 10 para Configuração de Dedos (CD); 6 para Orientação da Palma (OP); 35 para Ponto de Articulação (PA); e 44 para Movimento (M). Para registrar uma palavra em língua de sinais, o aprendiz precisa escrever primeiramente o grupo CD (observando-se inicialmente a posição do polegar e posteriormente a dos demais dedos). Logo em seguida, devem ser escritos os grupos OP, PA e M, obedecendo-se, sempre, essa ordem.

A CD refere-se ao formato em que os dedos das mãos estão representados. $A$ OP representa a posição inicial em que a palma da mão se encontra ao se produzir um sinal. O PA reforça a ideia de localização, ou seja, o local do corpo ou do espaço onde o sinal está sendo realizado. O grupo $\mathrm{M}$, por sua vez, diz respeito ao movimento em que o braço, os dedos, as mãos e as expressões não manuais se apresentam.

Para compreendermos a representação desse sistema, observemos o sinal 'ESTUDAR', em Libras, e o registo do sinal em ELiS, na Figura 1. 
Fig. 1 - Sinal 'ESTUDAR' em Libras
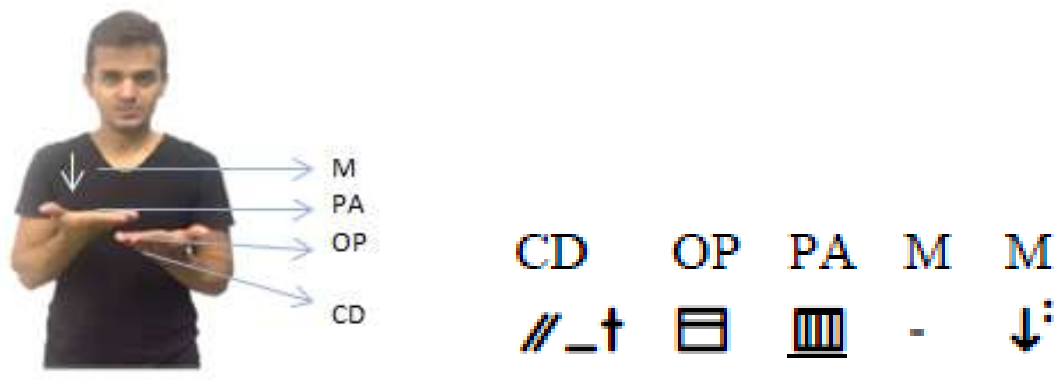

Fonte: Elaborado pelos autores.

Na Figura 1, observamos a representação do sinal 'ESTUDAR' em Libras e ELiS. Trata-se de um tipo de sinal bimanual quase simétrico. De acordo com Barros (2008), todo sinal bimanual simétrico ou quase simétrico deve utilizar-se do sinal de pontuação '//' para indicar que a CD, a OP, o PA e o M são iguais nas duas mãos. Nesse exemplo, por ser um sinal 'quase' simétrico, nem todas as unidades são iguais, como podemos observar no grupo de movimento. Nota-se que a mão esquerda apresenta ausência de movimento (M) que é representado por ' - '. Por sua vez, o M na mão direita é representado por ' $\downarrow$ ', acompanhado do diacrítico de repetição ':'. A configuração dos dedos (CD) representa o polegar na posição horizontal ' - ', tendo os dedos indicadores e demais dedos estendidos e unidos ' $\uparrow$ '. A orientação da palma (OP) se configura para cima ' $\boxminus$ ', e o ponto de articulação (PA) ocorre com os dedos da mão direita tocando os dedos da mão esquerda ' $⿴ 囗 ⿰ 丿 丨$ '.

Tendo apresentado os principais conceitos da ELiS, passemos à outra parte da fundamentação teórica deste artigo, que trata da teoria sociocultural e da aprendizagem colaborativa.

\subsection{A TEORIA SOCIOCULTURAL E A APRENDIZAGEM COLABORATIVA}

A teoria psicolinguística de Vygotsky, comumente conhecida por teoria sociocultural, tem por objetivo investigar e explicar o desenvolvimento cognitivo das crianças. Por ser uma teoria do desenvolvimento, tem sido também mundialmente utilizada em estudos sobre o processo de aquisição e de aprendizagem de línguas (BANKS-LEITE, 2000; CARVALHO, 2002; FIGUEIREDO, 2001, 2006, 2015; LANTOLF, 2000a, 2000b; VYGOTSKY, 1998). 
De acordo com Figueiredo (2001, p. 60),

[a] teoria sociocultural, baseada principalmente nos trabalhos de L. S. Vygotsky e seus colaboradores, tem como pressupostos que as atividades humanas: a) acontecem em contextos culturais, b) são mediadas pela linguagem ou outros sistemas simbólicos e c) podem ser melhor compreendidas quando investigadas no seu desenvolvimento histórico. (FIGUEIREDO, 2001, p. 60)

$\mathrm{Na}$ concepção vygostkiana, a linguagem tem um papel extremante relevante para o desenvolvimento da aprendizagem. Dessa forma, quando as atividades são mediadas, seja por instrumentos ou pela interação com outras pessoas, os indivíduos desenvolvem-se tanto interpsicologicamente (social) quanto intrapsicologicamente (individual).

Banks-Leite (2000, p. 35) afirma que, para Vygostky, a preocupação fundamental para o desenvolvimento do indivíduo é "com a interação social, pois é no plano intersubjetivo, ou seja, nas trocas do sujeito-outro/objeto social, que têm origem as funções superiores" (linguagem, comunicação, atenção, memória dedutiva e raciocínio), que são adquiridas, por exemplo, no contexto social e depois internalizadas.

Ao discorrer sobre a teoria sociocultural, Figueiredo $(2015$, p. 42) esclarece que o desenvolvimento psíquico das crianças "ocorre por meio da interação com crianças mais experientes e/ou com adultos". Vygostky (1998) distingue dois níveis de desenvolvimento da criança: o real e o potencial. O nível de desenvolvimento real refere-se ao estágio de desenvolvimento em que o indivíduo consegue realizar uma tarefa sem a ajuda de outra pessoa. Por sua vez, o nível de desenvolvimento potencial caracteriza-se pelas tarefas que o indivíduo pode vir a desempenhar por meio do auxílio de outra pessoa. Essa distância entre o nível de desenvolvimento real e o nível de desenvolvimento potencial é chamada de Zona de Desenvolvimento Proximal (ZPD) que é definida como

a distância entre o nível de desenvolvimento real, que se costuma determinar através da solução independente de problemas, e o nível de desenvolvimento potencial, determinado através da solução de problemas sob a orientação de um adulto ou em colaboração com companheiros mais capazes. (VYGOTSKY, 1998, p. 112) 
A ZDP é definida como o processo em que ocorre a aprendizagem e, conforme afirma Figueiredo (2001, 2005, 2006), é na interação dialógica entre os participantes que ocorrem tanto input quanto output. Por meio dessas interações "todos aprendem e não simplesmente o menos habilidoso ou o que tem menos conhecimento" (FIGUEIREDO, 2001, p. 63).

O uso de atividades interativas e colaborativas para a realização de tarefas tem sido uma estratégia bastante utilizada por professores durante suas aulas. Tal abordagem justifica-se pelo fato de um aluno poder ajudar o outro a tirar dúvidas, a desenvolver estratégias de estudos e, principalmente, tornar um ambiente agradável para aprendizagem (FIGUEIREDO, 2006; FIGUEIREDO; ARAÚJO, 2018).

Por meio do diálogo, os alunos podem oferecer uns aos outros scaffoldings ${ }^{9}$ que os auxiliarão na execução de suas tarefas (WOOD; BRUNNER; ROSS, 1976). Wood, Bruner e Ross (1976, p. 90) afirmam que o scaffolding "pode resultar, eventualmente, no desenvolvimento da competência de realizar a tarefa pelo aprendiz num ritmo que ultrapassaria seus esforços não assistidos”. Assim, as interações em sala de aula, ou fora dela, são vistas de forma positiva, pois o diálogo colaborativo nos dá a oportunidade de aprender com o outro, de respeitar-se, de descontruir ideias, de aprender e, principalmente, de refletir sobre nossas ações como seres humanos.

A aprendizagem colaborativa é concebida como todo "processo de aprendizagem: alunos ensinando a alunos; alunos ensinando ao professor; 0 professor ensinando aos alunos" (FIGUEIREDO, 2006, p. 19). Essa abordagem, por sua vez, permite que aconteçam trocas de conhecimentos que vão além dos processos de aprendizagem, ou seja, dando aos alunos e professores a oportunidade de um aprender com o outro, fazendo com que se tornem atuantes e mediadores desse processo (FIGUEIREDO; OLIVEIRA, 2017).

Conforme afirmam Alcântara, Siqueira e Valaski (2004, p. 3, grifo dos autores),

\footnotetext{
8 De acordo com Figueiredo (2015), input refere-se às mensagens ou informações linguísticas que um aprendiz recebe e que podem ou não ser assimiladas. O output, por sua vez, refere-se à produção linguística, seja escrita ou oral. Para mais detalhes sobre as funções do input e do output nos processos de aquisição e aprendizagem de línguas, veja, por exemplo, Krashen (1978) e Swain (1985).

${ }^{9}$ A metáfora do scaffolding é compreendida como um apoio dado a uma criança para realizar uma determinada tarefa, algo que ela não conseguiria fazer sem a ajuda de um par mais competente (WOOD; BRUNNER; ROSS, 1976).
} 
[a] aprendizagem colaborativa pressupõe um ambiente de aprendizagem aberto em que o aluno se envolve a "fazer coisas e a refletir sobre o que faz", sendo-lhe dada a oportunidade de pensar por si mesmo e de comparar o seu processo de pensamento com o dos outros, estimulando, assim, o pensamento crítico. (ALCÂNTARA; SIQUEIRA; VALASKI, 2004, p. 3, grifo dos autores)

Dessa forma, como pressupõe a aprendizagem colaborativa, os aprendizes podem descobrir novas formas de aprender uns com os outros, levando, também, os alunos mais experientes a ampliar seu conhecimento e a aprender ainda mais (FIGUEIREDO, 2006). Nesse contexto de mediação entre os participantes, as oportunidades de negociação no compartilhamento de input e de output são relevantes. É por meio dessa mediação que ocorre a participação ativa de todos os sujeitos, o que promove um ambiente de apoio dinâmico e atrativo entre eles.

\section{O ESTUDO}

Os dados para este artigo advêm da pesquisa realizada por Freitas (2016), que ocorreu nas dependências da Faculdade de Letras, no curso de Letras: Libras da UFG, campus Goiânia. Participaram da pesquisa quatro alunos surdos do 5 o período do curso, todos fluentes em Libras e em ELiS. Eles produziram textos em ELiS inicialmente de forma individual e, posteriormente, com a colaboração de um par. Os participantes escolheram com quem iriam realizar a tarefa de produção textual e, para preservar-lhes a identidade, eles escolheram para si codinomes. As duplas ficaram assim definidas: Ana Linda e Isabela; Helena e Mário.

Este estudo de caso (MOREIRA; CALEFFE, 2008) teve por objetivo investigar os efeitos da interação e da colaboração na produção de textos em ELiS escritos pelos participantes surdos. Objetivou também identificar, por meio de entrevistas em Libras, as percepções que eles tiveram ao realizar as tarefas de forma individual e colaborativa.

Foram utilizados como instrumentos para a coleta de dados: entrevistas, para obter as percepções dos alunos sobre trabalhar individualmente $\mathrm{e}$ colaborativamente; gravações das interações, para verificar as estratégias e negociações que os participantes realizavam; e duas narrativas, que foram 
gravadas, em Libras, por um dos pesquisadores e projetadas no quadro branco em sala de aula. Depois de projetada o início da história, os participantes teriam de desenvolvê-la escrevendo em ELiS.

Para a realização das tarefas, a pesquisa se pautou em quatro encontros. No primeiro encontro, iniciamos a aula exemplificando o contexto da pesquisa mencionando que se tratava de uma pesquisa sem fins lucrativos e que a participação deles não era obrigatória. Ao verificar que todos tiveram interesse em atuar na pesquisa, a professora da disciplina de ELiS 2 se mostrou entusiasmada com a proposta de atividade e avisou-lhes que a realização das atividades de escrita, individual e colaborativa, teria um caráter avaliativo no decorrer da disciplina. Além disso, nesse mesmo dia, entregamos um questionário para obter informações dos alunos, como, por exemplo: a idade, o interesse pela aprendizagem de Libras, as dificuldades que encontram e, também, sobre as estratégias que utilizam para aprender a língua.

No segundo encontro, os alunos escreveram em ELiS, de forma individual, o início da história que Ihes foi sinalizada e, posteriormente, davam continuidade à narrativa a partir da criatividade deles. Essa tarefa só foi finalizada na aula do dia seguinte. No terceiro encontro, a tarefa foi realizada de forma colaborativa. Apresentamos o início de outra história, e os participantes teriam de terminá-la em duplas. Essa atividade começou e terminou no mesmo dia. Por fim, no quarto encontro, entrevistamos os participantes, individualmente, para que pudéssemos obter a percepção deles ao trabalharem individualmente e com o colega.

Para fins de ilustração das histórias sinalizadas em Libras nesta pesquisa, vejamos as Figuras 2 e 3 :

\section{Fig. 2 - História realizada no contexto individual}

\section{COMPRAS NA FEIRA}

Domingo passado fui à feira e comprei laranja, maçã, limão, melancia. Todas as frutas estavam com preço muito alto. Eu não poderia me esquecer de comprar tomates, mas estava sem dinheiro.

Foi então que vi um amigo ...

Fonte: FREITAS, 2016, p. 62.

Pensares em Revista, São Gonçalo-RJ, n. 14, p. 52-73, 2019

DOI: $10.12957 /$ pr.2019.37188 
Fig. 3 - História realizada no contexto em pares

DOIS IRMÃos
Era uma vez dois irmãos, Paulo e Carlos. Os dois viviam na floresta junto com sua
família. Paulo era o filho mais jovem e trabalhava junto com seu pai na floresta. Carlos era uma
pessoa muito doente e não trabalhava.
Num dia ...

Fonte: FREITAS, 2016, p. 63.

Após a coleta de dados, nossas análises tiveram por foco as interações entre os participantes deste estudo ao escreverem colaborativamente, bem como as percepções que tiveram durante a realização das duas tarefas: quando escreveram os textos sozinhos e com o colega. Para a análise dos dados apoiamo-nos nos estudos de Alcântara, Siqueira e Valaski (2004), Carvalho (2002), Figueiredo (2001, 2005, 2006, 2015) e Vygotsky (1998), por reconhecerem a importância da interação e da colaboração no desenvolvimento dos indivíduos.

\section{RESULTADOS}

A análise dos dados se divide em duas partes. Na primeira, analisamos as interações em Libras na produção dos textos em ELiS. Na segunda, analisamos as percepções dos alunos sobre o processo de escrever em ELiS individualmente e colaborativamente.

\subsection{ANÁLISE DAS INTERAÇÕES EM LIBRAS NA PRODUÇÃO DOS TEXTOS EM ELIS}

Neste estudo, fizemos a tradução de toda a fala dos participantes em Libras para o português. Passemos, então, à analise das interações realizadas pelos pares: Ana Linda e Isabela; Helena e Mário.

No excerto 1, Ana Linda e Isabela iniciaram o texto dialogando sobre a melhor forma de escrever os nomes dos personagens: Paulo e Carlos. As participantes estão discutindo sobre o espaço de sinalização em que representariam os 
personagens ${ }^{10}$. Observa-se que Ana Linda menciona que um personagem deve estar no lado esquerdo e o outro do lado direito.

[1] Ana Linda: Agora, a gente precisa escrever P-A-U-L-O.

Isabela: Sim, mas antes precisa escrever sinal de nome, né?

Ana Linda: Não! É só você colocar a pessoa aqui, olha ... (mostrando para a colega que o sinal deve ser feito com o dedo polegar e indicador curvos, demais dedos fechados, o movimento para baixo e a palma para frente). Aí, colocamos do lado direito aqui no espaço neutro P-A-U-L-O e, do lado esquerdo, a gente coloca o nome do C-A-R-L-O-S. Eu acho que é melhor colocarmos sem o sinal de nome, porque se a gente usar este sinal aqui (o descrito anteriormente por ela) já indica pessoa, né?

Isabela: Hum, entendi.

Ana Linda: Então, como é o sinal de marcar mesmo?

Isabela: No vídeo está assim, olha (e repete o sinal feito por Ana Linda anteriormente).

Ana Linda: Hum, deixa eu pensar ...

Isabela: A configuração de dedos é realizada com o polegar e o indicador curvos, olha (mostrando como o sinal é feito).

Ana Linda: Sim! Mas, primeiro escreve o sinal de pessoa para P-A- U-L-O.

Isabela: Ok.

Ana Linda: Olha (continua mostrando o sinal).

Isabela: Isso aí, agora escreve P-A-U-L-O.

Ana Linda: Ok.

(Trecho retirado da interação de Ana Linda e Isabela)

Fonte: FREITAS, 2016, p. 131.

Como vimos nesse trecho, as participantes negociam (ALCÂNTARA; SIQUEIRA; VALASKI, 2004; BASSI, 2006) constantemente sobre como marcar, no espaço, os personagens 'P-A-U-L-O' e 'C-A-R-L-O-S'. Além disso, para tornar o sentido da palavra e do texto compreensíveis, Ana Linda e Isabela utilizaram a estratégia de mostrar para a outra, em Libras, o sinal, e depois escreviam em ELiS. Dessa forma, o input compreensível somente foi suficiente quando a ajuda da colega foi recíproca (KRASHEN, 1978).

A partir dessa interação, podemos observar a importância da colaboração no processo de escrita em línguas de sinais, uma vez que demanda de muita atenção e cuidado para identificar elementos que poderiam não ser observados, caso escrevessem os textos sozinhos. Observa-se que as participantes não dialogam apenas sobre a estrutura do sinal, isto é, a posição dos dedos, o movimento etc.

${ }^{10} \mathrm{Em}$ Libras, ao se contar uma história, quando há mais de um personagem, estes são marcados no espaço em frente ao corpo de quem sinaliza. Esse recurso é utilizado para facilitar a compreensão dos personagens conforme a história é contada (COSTA, 2015). 
Elas discutem também sobre a sintaxe da língua (QUADROS; KARNOPP, 2004; SANDLER, 2010), quando refletem sobre a marcação dos personagens no espaço de enunciação.

O trecho 2 mostra um outro momento de interação de Ana Linda e Isabela. As participantes dialogam sobre a maneira correta de escrever o sinal 'HOMEM'. Neste excerto, podemos observar que as aprendizes puderam ampliar conhecimento linguístico relacionado às estruturas gramaticais e lexicais do sinal sobre o qual discutiam. Além disso, observamos que a participante mais experiente, Ana Linda, pôde auxiliar Isabela a compreender a forma correta do sinal, oferecendo-Ihe scaffolding explícito (WOOD, BRUNNER, ROSS, 1976), ou seja, corrigindo-a e mostrando a ela a forma correta da configuração de dedo para o referido sinal. Vejamos a interação entre elas.

[2] Isabela: O sinal 'HOMEM' é assim, olha (mostrando como o sinal é feito, tendo o movimento para baixo e a configuração dos dedos na letra $C$ e o ponto de articulação no queixo).

Ana Linda: Não, é assim. O sinal de 'HOMEM' tem dois movimentos, olha (mostrando como o sinal é feito, tendo o movimento para baixo, e as pontas dos dedos se tocando no movimento de fechar a mão. A participante também explica à colega que a configuração de dedos não é na letra $C$, mas, sim, com os dedos inclinados).

Isabela: Ah, sim! Entendi. Mas a locação é no queixo, né?

Ana Linda: Justamente. Agora precisamos escrever 'IRMÃOS'.

(Trecho retirado da interação entre Ana Linda e Isabela)

Fonte: FREITAS, 2016, p. 130.

Nesse trecho, Ana Linda e Isabela discutem sobre o sinal 'HOMEM'. Isabela afirma que o sinal tem a configuração de dedos (CD) representada pela letra "C", o movimento (M) "para baixo" e locação (PA) no "queixo". Ana Linda chama a atenção de Isabela, afirmando que o sinal 'HOMEM' têm dois movimentos, e não um movimento como afirma sua parceira. $E$ também explica que a CD não é na letra " $C$ ", mas, sim, com todos os dedos "estendidos e inclinados".

A interação entre Ana Lina e Isabela, ao discutirem sobre a forma do sinal 'HOMEM', fez com que a aluna com mais habilidade na escrita, no caso Ana Linda, interviesse na ZDP da colega (CARVALHO, 2002; FIGUEIREDO, 2001, 2006, 2015; VYGOSTKY, 1998). Esse auxílio possibilitou à Isabela compreender o sinal 
'HOMEM', por meio do scaffolding oferecido por sua colega (WOOD; BRUNER, ROSS, 1976).

De modo a verificar a escrita do sinal 'HOMEM', a partir da interação realizada entre as participantes, observe na figura 4, a seguir:

Fig. 4 - Sinal 'HOMEM'.

Fonte: FREITAS, 2016, p. 100.

No excerto 3, dando continuidade à discussão do sinal 'HOMEM', o outro par de participantes, Mário e Helena, dialogam sobre a produção do sinal 'IGUAIS'. No diálogo, a seguir, podemos observar a solicitação de scaffolding por meio de uma pergunta feita por Helena: "como é o sinal, mostra aí?". Mário provê à parceira a resposta correta, mostrando a ela como o sinal é produzido. A interação com a colega faz com que o aluno perceba que o movimento do sinal não é simultâneo, mas, sim, alternado. Podemos, neste diálogo, notar que os alunos se ajudam mutuamente tanto na produção correta do sinal como na forma de representá-lo em ELiS, o que ilustra um processo de coconstrução de conhecimento (FIGUEIREDO, 2006; LANTOLF, 2000b; SWAIN; BROOKS; TOCALLI-BELLER, 2012; VYGOTSKY, 1998).

[3] Helena: Agora, iguais (Helena produz o sinal 'IGUAIS' para a colega), como é o sinal, mostra aí?

Mário: $\quad$ Olha (mostrando para Helena o sinal 'IRMÃOS', tendo a pontuação da ELiS para indicar o sinal de duas mãos, a configuração dos dedos com os indicadores estendidos e demais dedos fechados, ponto de articulação na lateral dos dedos e o movimento para frente e para trás alternado).

Helena: Vou escrever. Pronto. Olha aqui (mostrando o sinal de 'IGUAIS')

Mário: $\quad$ Mas tem movimento de repetição, Helena!

Helena: Não, o movimento é alternado, porque, se colocar repetição, as duas mãos vão para frente e para trás.

Mário: $\quad$ Ah, verdade (momento em que Mário percebe que o movimento é alternado). Você está certa.

Helena: (Risos)

(Trecho retirado da interação de Helena e Mário)

Fonte: FREITAS, 2016, p. 133. 
Essa interação, por meio da qual os alunos refletem sobre a posição dos dedos polegares, indicadores, médios, anelares e mínimos e sobre o tipo de movimento requerido na produção do sinal, nos mostra que os alunos estão sempre se corrigindo e atentos à forma como o sinal é realizado. Por meio dessa interação, podemos observar, por exemplo, a riqueza de momentos colaborativos em sala de aula, principalmente em contextos que envolvem a Libras, pois, por ser uma língua visuoespacial, sua aprendizagem é favorecida quando os aprendizes têm a oportunidade de observar, com atenção, como os sinais são produzidos.

Os dados acima nos mostram que, por meio das relações dialógicas entre os participantes na colaboração, os alunos puderam ter a oportunidade de desconstruir hipóteses já internalizadas, ao perceberem, por exemplo, que um sinal era feito de uma forma diferente do que pensavam, como ocorreu com o sinal 'HOMEM'.

\subsection{ANÁLISE DAS PERCEPÇÕES DOS ALUNOS SOBRE O PROCESSO DE ESCREVER EM ELIS INDIVIDUALMENTE E COLABORATIVAMENTE}

Com base nos dados apresentados neste estudo, podemos afirmar que as tarefas colaborativas favorecem a produção correta de sinais em Libras e, principalmente, a produção de textos em ELiS, conforme observado por Freitas (2016) em seu estudo.

Como pontos positivos relatados pelos participantes desta pesquisa e que dialogam com as pesquisas de Carvalho (2002) e Wobeto (2012), temos: a oportunidade de os alunos trocarem conhecimento por meio de auxílio realizado entre eles; e oportunidade de se corrigirem, aumentando-lhes as chances de resolverem suas dúvidas.

A partir dessas reflexões, observemos, no Quadro 1, as percepções dos participantes sobre escrever individualmente e com o colega.

Quadro 1: Pontos positivos e negativos sobre escreverem o texto sozinhos e com o colega Pontos positivos Pontos negativos 


\begin{tabular}{|c|c|c|c|}
\hline Escrever individualmente & $\checkmark$ & $\begin{array}{l}\text { Oportunidade de } \\
\text { autonomia para escrever } \\
\text { o texto. }\end{array}$ & $\begin{array}{l}\checkmark \\
\text { Dificuldade em } \\
\text { escreverem o texto e não } \\
\text { terem com quem tirar as } \\
\text { dúvidas. } \\
\text { Insegurança para escrever } \\
\text { o sinal em ELiS. }\end{array}$ \\
\hline Escrever colaborativamente & $\checkmark$ & $\begin{array}{l}\text { Possibilidade de trocar } \\
\text { conhecimentos } \\
\text { envolvendo os aspectos } \\
\text { da escrita. } \\
\text { Possibilidade de reflexão } \\
\text { sobre a escrita. } \\
\text { Oportunidade de se } \\
\text { corrigirem. }\end{array}$ & \\
\hline
\end{tabular}

Fonte: FREITAS, 2016, p. 110.

Ao falarem sobre a experiência de trabalhar colaborativamente, Ana Linda e Isabela afirmaram que, por meio do diálogo ocorrido, puderam se corrigir e refletir sobre a escrita. Além disso, relataram a possibilidade de trocarem conhecimento, visto que uma ajudava a outra nesse processo de aprendizagem. Vejamos, por exemplo, o relato das participantes no que diz respeito à oportunidade de se corrigirem quando escreviam em ELiS.

\section{Oportunidade de se corrigirem}

[4] Pesquisador: Você gostaria de falar mais alguma coisa sobre seu processo de escrever em ELiS com sua colega?

Isabela: $\quad$ Bom, eu acho que, ao trabalhar com meu colega, pude melhorar mais na escrita. Escrever sozinha, para mim, foi muito ruim por não lembrar de alguns visografemas. Também, por não saber escrever o sinal, ficava complicado e acabava escrevendo sem ter certeza. Já quando estive com minha colega, ela acabava me corrigindo.

[5] Pesquisador: Você viu pontos positivos em escrever em dupla?

Ana Linda: $\quad$ Eu gostei pelo fato de a minha amiga poder representar o sinal em Libras para mim. Com isso, ficava mais fácil o processo de escrita. Outra coisa também era que eu escrevia o sinal, e minha amiga lia o sinal para que, assim, não tivéssemos nenhum problema, né?

(Trecho da entrevista de Isabela e Ana Linda)

Fonte: FREITAS, 2016, p. 114.

\section{Possibilidade de trocar conhecimentos envolvendo os aspectos da escrita}

[6] Pesquisador: Você gostaria de falar mais alguma coisa sobre seu processo de escrever em ELiS com seu colega?

Helena: $\quad$ Eu gostei bastante. Porque tive a oportunidade de tirar dúvidas com meu 
colega.

[7] Pesquisador: Você viu pontos positivos em escrever em dupla?

Mário: $\quad$ Eu acho que essa troca de conhecimentos, né? Porque, assim, eu tenho dificuldade, e minha amiga é inteligente e, assim, ela acabou me ensinando algumas coisas da ELiS, como a configuração de dedos e os tipos de movimentos.

(Trechos da entrevista de Helena e Mário)

Fonte: FREITAS, 2016, p. 113.

Por meio das entrevistas, notamos que o trabalho colaborativo mostrou-se frutífero para o processo de aprendizagem dos participantes, pois criou um ambiente saudável em sala de aula, dando a oportunidade a eles de refletirem sobre a produção de sinais em libras, bem como de juntos construírem conhecimento.

Embora esses participantes não tenham relatado aspectos negativos sobre trabalhar colaborativamente, na literatura há diversas pesquisas que relatam alguns pontos negativos (veja, por exemplo, CARVALHO, 2002; FIGUEIREDO, 2001; WOBETO, 2012, entre outros). Sobre trabalhar individualmente, apresentamos os relatos de Helena, Ana Linda e Isabela, em que afirmam se sentirem inseguras e com dificuldades ao escreverem os textos.

\section{Dificuldade e insegurança ao escrever em ELiS}

[8] Pesquisador: Você teve alguma dificuldade em escrever o texto individualmente? Helena: $\quad$ Nossa, eu tive algumas, sabe? Por exemplo, quando eu ia escrever um sinal, eu acabava esquecendo o movimento, principalmente nos sinais que têm mais de um movimento.

[9] Pesquisador: Quais pontos negativos em escrever individualmente?

Ana Linda: $\quad$ No início, eu achei que escrever sozinho fosse melhor. Logo, percebi que eu precisava adaptar a história, né? Porque alguns sinais tinham mais de um movimento, eu sempre confundia achando que era apenas um, como, por exemplo, o sinal de 'DIFÍCIL'. Parece que tem apenas um movimento, né? Mas, na verdade, têm dois movimentos, e isso eu não conseguia decidir e compreender.

(Trechos da entrevista de Helena e Ana Linda)

Fonte: FREITAS, 2016, p. 111.

Esses relatos corroboram a importância do trabalho colaborativo na produção de textos em ELiS, visto que, com o auxílio do colega, os alunos podem perceber como os sinais são realizados e, assim, escrevê-los corretamente. 


\section{CONSIDERAÇÕES FINAIS}

Observamos, por meio deste estudo, que as interações em língua de sinais também ajudaram os alunos a aprender mais e a esclarecer dúvidas quanto à forma como os sinais são produzidos em Libras. Vimos que, por meio da interação, os participantes fazem perguntas uns aos outros e chamam a atenção do parceiro para algum aspecto dos sinais, como, por exemplo: "Olha aqui, está certo?". "Como é mesmo o sinal de (...)?" "Não, o movimento é alternado, porque, se colocar repetição, as duas mãos vão para frente e para trás".

Essas perguntas nos mostram que os alunos estão desempenhando um papel mais ativo no seu processo de aprendizagem e refletindo, por meio do auxílio do colega, sobre as configurações dos sinais em Libras. Essas reflexões podem tornarse escassas quando trabalham individualmente.

É evidente nessas interações a coconstrução de conhecimento ao conversarem sobre a estrutura correta em escrever um sinal em Libras/ELiS. Além disso, notamos uma troca de scaffoldings frequente quando um participante perguntava e corrigia o colega sobre o movimento, ou, até mesmo, quando discutiam sobre a forma de se marcarem, no espaço de enunciação, as posições dos personagens da narrativa que escreveram. Esses dados nos mostraram que, conforme afirmam Wood, Bruner e Ross (1976), os alunos puderam receber ajuda, trocar informações linguísticas, aprender, compreender, refletir e desconstruir hipóteses errôneas ao trabalharem em um contexto colaborativo.

Conforme mencionado pelos participantes, a aprendizagem em pares configurou-se, para eles, como um ambiente agradável e de oportunidades para refletir sobre diversas características peculiares que a Libras apresenta, feito que dificilmente aconteceu quando trabalharam individualmente. Dessa forma, convidamos os professores de Libras e de ELiS a fazerem um uso mais frequente da colaboração em suas aulas.

\section{REFERÊNCIAS}


ALCÂNTARA, P. R.; SIQUEIRA, L. M. M.; VALASKI, S. Vivenciando a aprendizagem colaborativa em sala de aula: experiências no ensino superior. Revista Diálogo Educacional, Curitiba, v. 4, n. 12, p. 169-188, 2004.

BANKS-LEITE, L. As dimensões interacionista e construtivista em Vygotsky e Piaget. Caderno Cedes, Campinas, n. 24, p. 31-37, 2000.

BARROS, M. E. ELiS - escrita das línguas de sinais: proposta teórica e verificação prática. 2008. 192 f. Tese (Doutorado em Linguística) - Centro de Comunicação e Expressão, Universidade Federal de Santa Catarina, Florianópolis, 2008. Penso, 2015.

ELiS: sistema brasileiro de escrita das línguas de sinais. Porto Alegre: Ed.

. Princípios básicos da ELiS: Escrita das línguas de sinais. Revista Sinalizar, Goiânia, v.1, n. 2, p. 204-210, jul./dez. 2016.

BASSI, C. E. O efeito de negociações: uma análise do processo de co-construção de textos em língua francesa. In: FIGUEIREDO., F. J. Q. de. (org.). A aprendizagem colaborativa de línguas. Goiânia: Ed. UFG, 2006. p.143-164.

CARVALHO, G. de O. Revisão colaborativa de textos escritos em língua inglesa por alunos iniciantes do curso de Letras. 2002. 169 f. Dissertação (Mestrado em Letras e Linguística) - Faculdade de Letras, Universidade Federal de Goiás, Goiânia, 2002.

COSTA, A. C. L. da. A sinalização de histórias em Libras: aspectos linguísticos e extralinguísticos. 2015. 154 f. Dissertação (Mestrado em Letras e Linguística) Faculdade de Letras, Universidade Federal de Goiás, Goiânia, 2015.

FAULSTICH, E. Modalidade oral-auditiva versus modalidade vísuo-espacial sob a perspectiva de dicionários na área da surdez. In: LIMA-SALLES, H. M. M. (org.). Bilinguismo dos surdos: questões linguísticas e educacionais. Goiânia: Cânone Editorial, 2007. p. 143-157.

FELIPE, T. A. Libras em contexto: curso básico, livro do estudante cursista. Brasília: Programa Nacional de Apoio à Educação de Surdos, MEC; SEESP, 2001.

FERNANDES, L. A. A viabilidade da ELiS em vinte línguas de sinais. 2013. $133 \mathrm{f}$. Trabalho de Conclusão de Curso (Licenciatura em Letras: Libras) - Faculdade de Letras, Universidade Federal de Goiás, Goiânia, 2013.

FIGUEIREDO, F. J. Q. de. Correção com os pares: os efeitos do processo da correção dialogada na aprendizagem da escrita em língua inglesa. 2001. 340 f. Tese (Doutorado em Linguística Aplicada) - Faculdade de Letras, Universidade Federal de Minas Gerais, Belo Horizonte, 2001. 
. A aprendizagem colaborativa de línguas: algumas considerações conceituais e terminológicas. In: línguas. Goiânia: Ed. UFG, 2006. p. 11-45. (org.). A aprendizagem colaborativa de Aprendendo com os erros: uma perspectiva comunicativa de ensino de línguas. 3. ed. rev. ampl. Goiânia: Ed. UFG, 2015.

FIGUEIREDO, F. J. Q. de.; ARAÚJO, M. A. F. Possibilidades de aprendizagem por meio do uso de jogos em sala de aula de inglês. In: FIGUEIREDO, F. J. Q. de; SIMÕES, D. (org.). Contribuições da linguística aplicada para a educação básica. Campinas: Pontes, 2018. p. 245-272.

FREITAS, G. G. de. A produção textual em Escrita das Línguas de Sinais (ELiS): um contraste entre a escrita individual e a escrita colaborativa realizadas por alunos surdos. 2016. $147 \mathrm{f}$. Trabalho de Conclusão de Curso (Licenciatura em Letras: Libras) - Faculdade de Letras, Universidade Federal de Goiás, Goiânia, 2016.

KRASHEN, S. D. The Monitor Model for Second-Language Acquisition. In: GINGRAS, R. C. (org.). Second-Language Acquisition \& Foreign Language Teaching. Washington: Center for Applied Linguistics, 1978. p. 1-26.

LANTOLF, J. P. (Ed.). Sociocultural Theory and Second Language Learning. Hong Kong: Oxford University Press, 2000a.

. Second Language Learning as Mediated Process. Language Teaching, Cambridge, v. 33, p. 79-96, 2000b.

MOREIRA, H.; CALEFFE, L. G. Metodologia de pesquisa para o professor pesquisador. 2. ed. Rio de Janeiro: Lamparina, 2008.

NUNAN, D. Methods in Second Language Classroom-Oriented Research. Studies in Second Language Acquisition, Cambridge, v. 13, n. 2, p. 249-274, 1991.

OLIVEIRA-SILVA, C. M. A aprendizagem colaborativa de inglês instrumental por alunos surdos: um estudo com alunos do curso de Letras: Libras da UFG. 2017. 286 f. Tese (Doutorado em Letras e Linguística) - Faculdade de Letras, Universidade Federal de Goiás, Goiânia, 2017.

OLIVEIRA, Q. M. de.; FIGUEIREDO, F. J. Q. de. Aprendizagem de libras e português em contexto de tandem: um estudo realizado com uma aluna surda e uma aluna ouvinte da Universidade Federal de Tocantins. Caderno Seminal Digital, Rio de Janeiro, v. 28, n. 28, 2017.

QUADROS, R. M; KARNOPP. L. B. Língua de sinais brasileira: estudos linguísticos. Porto Alegre: Artmed. 2004. 
QUADROS, R. M. de; SCHMIEDT, M. L. P. Ideias para ensinar português para alunos surdos. Brasília: MEC; SEESP, 2006.

SANDLER, W. Prosody and Syntax in Sign Languages. Transactions of the Philological Society, Haifa, v. 108, n. 3, p. 298-328, 2010.

SWAIN, M. Communicative Competence: Some Roles of Comprehensible Input and Comprehensible Output in its Development. In: GASS, S. M.; MADDEN, C. C. (org.). Input in Second Language Acquisition. Rowley: Newbury House, 1985. p. 235252.

SWAIN, M.; BROOKS, L.; TOCALLI-BELLER, A. Peer-peer Dialogue as a Means of Second Language Learning. Annual Review of Applied Linguistics, Cambridge, v. 22, p. 171-185, 2002.

VYGOTSKY, L. S. A formação social da mente: o desenvolvimento dos processos psicológicos superiores. São Paulo: M. Fontes, 1998.

WOBETO, R. Produção colaborativa de textos escritos em língua inglesa: um estudo de caso. 2012. 159 f. Dissertação (Mestrado em Letras e Linguística) Faculdade de Letras, Universidade Federal de Goiás, Goiânia, 2012.

WOOD, D.; BRUNER, J. S.; ROSS, G. The Role of Tutoring in Problem Solving. Journal of Child Psychology and Psychiatry, London, v. 17, p. 89-100, 1976.

\section{Sobre os autores \\ Guilherme Gonçalves de Freitas \\ Graduado pela Universidade Federal de Goiás (UFG) no curso de licenciatura em Letras: Libras e Especialista em Linguística das Línguas de Sinais pela UFG. Atualmente é mestrando em Estudos Linguísticos pela UFG e graduando do curso de Pedagogia Bilíngue pelo Instituto Federal de Goiás (IFG). Tem experiência com ensino de Libras e ELiS. \\ Francisco José Quaresma de Figueiredo \\ Professor Titular de Língua Inglesa na Universidade Federal de Goiás. Graduado em Letras - Português e Inglês e Mestre em Linguística pela mesma universidade. Doutor e Pós-Doutor em Linguística Aplicada (LA) pela Universidade Federal de Minas Gerais. Tem experiência na área de LA, com ênfase nas seguintes áreas: ensino e aprendizagem de línguas, correção, erros, crenças, telecolaboração e formação de professores.}

